\title{
10 Years of Experience with the First Thawed Plasma Bank in Germany
}

\author{
Kathleen Selleng Andreas Greinacher \\ Institut für Immunologie und Transfusionsmedizin, Abteilung Transfusionsmedizin, Universitätsmedizin Greifswald, \\ Greifswald, Germany
}

\section{Keywords}

Thawed plasma bank · Liquid plasma $\cdot$ Clotting factor stability

\begin{abstract}
Background: Plasma is stored at $-30^{\circ} \mathrm{C}$, which requires thawing before transfusion, causing a time delay between ordering and issuing of at least $30 \mathrm{~min}$. In case of bleeding emergencies, guidelines strongly recommend a 2:1 transfusion ratio of RBCs and plasma. In addition, each minute delay in issuing of blood products in bleeding emergencies increases the mortality risk. To provide plasma in time in bleeding emergencies, a thawed plasma bank was introduced in 2011. Summary: The thawed plasma bank of University Medicine Greifswald has provided 18,924 thawed stored plasma units between 2011 and 2020. The workflow in the laboratory as well as in the emergency room, the operating room, and the intensive care unit have been optimized by thawed stored plasma. In case of emergencies, the stress factor for the transfusion medicine laboratory staff has been reduced substantially. The thawed plasma bank allows to transfuse patients with massive transfusion demand at a 2:1 ratio of RBCs and plasma according to guidelines. To reduce storage time, we issue all plasma requests from the thawed plasma bank except for pediatric patients. This results in a median storage time in the thawed plasma bank of $24 \mathrm{~h}$. The "just in time" availability of plasma within the entire hospital based on the thawed plasma bank has reduced precautionary ordering of plasma, and hereby the unnecessary use of plasma. After introduction of the thawed plasma bank, plasma usage decreased substantially by $24 \%$ within the first year and by $60 \%$
\end{abstract}

compared to $2019 / 2020$. However, as the overall approach to using blood products has changed over the last 10 years due to the patient blood management initiative, quantification of the effects of the thawed plasma bank in reduction of plasma transfusion is difficult. Key Messages: (1) A thawed plasma bank for the routine supply of blood products in a large hospital is feasible in Germany. (2) The thawed plasma bank allows to supply RBCs and plasma in a 2:1 ratio in bleeding emergencies. (3) The beneficial logistical effects of the thawed plasma bank are optimal if all plasma requests are supplied from the thawed plasma bank. This results in a median storage time of $24 \mathrm{~h}$ for thawed plasma.

\section{(c) 2021 The Author(s)}

Published by S. Karger AG, Basel

\section{Introduction}

Major blood loss is one of the few indications to transfuse plasma [1]. Further indications are deficiency in clotting factors for which no factor concentrates are available like for factor $\mathrm{V}$, improvement of hemostasis in coagulopathy, e.g., in case of liver impairment, increased general clotting factor consumption, plasma exchange for thrombotic thrombocytopenic purpura, and other rare indications [1].

In case of massive blood loss, it becomes increasingly clear that early plasma transfusion and maintenance of a red cells to plasma and single donor buffy coat platelets transfusion ratio of at least 2:1:1 improve patient outcome [2-7]. In this situation, plasma transfusion should be started as early as possible. In a prospective trial, each minute from activation of a massive transfusion protocol
(C) 2021 The Author(s)

Published by S. Karger AG, Basel

This article is licensed under the Creative Commons Attribution 4.0 International License (CC BY) (http://www.karger.com/Services/ OpenAccessLicense). Usage, derivative works and distribution are permitted provided that proper credit is given to the author and the original publisher.
Correspondence to:

Kathleen Selleng, kathleen.selleng@med.uni-greifswald.de 
Table 1. Therapeutic plasma formulations [22]

\begin{tabular}{|c|c|c|c|c|c|c|}
\hline Plasma formulation & Abbreviation & Processing & $\begin{array}{l}\text { Preparation } \\
\text { time (ready } \\
\text { to use), min }\end{array}$ & $\begin{array}{l}\text { Storage } \\
\text { temperature, } \\
{ }^{\circ} \mathrm{C}\end{array}$ & Shelf life & $\begin{array}{l}\text { Approval } \\
\text { by German } \\
\text { regulatory } \\
\text { body }\end{array}$ \\
\hline Fresh frozen plasma & FFP & frozen within $8 \mathrm{~h}$ & $30-45$ & $<-30$ & $2-3$ years & yes \\
\hline Thawed FFP & tFFP & thawed FFP & 0 & $2-6$ & up to 7 days & no \\
\hline Liquid plasma & LP & not frozen & 0 & $2-6$ & 26 days & no \\
\hline Plasma, frozen within $24 \mathrm{~h}$ & FP24 & frozen within 8-24 & h45 & -20 & 365 days & no \\
\hline \multirow[t]{3}{*}{ Dried plasma } & Lyoplas (German Red Cross) & freeze-drying & few minutes & $2-25$ & 15 months & yes \\
\hline & FLYP (France) & freeze-drying & 6 & $\begin{array}{l}\text { room } \\
\text { temperature }\end{array}$ & 2 years & no \\
\hline & Bioplasma FDP (South Africa) & freeze-drying & $<10$ & $<25$ & & no \\
\hline Under development & $\begin{array}{l}\text { spray-dried plasma (on-demand plasma), } \\
\text { Entegrion Inc. (Research Triangle Park, NC, USA) } \\
\text { partnered with Kedrion S.p.A (Barga, Lucca, } \\
\text { Italy) }\end{array}$ & spray-drying & 5 & $?$ & $?$ & \\
\hline
\end{tabular}

to arrival of the cooling container at the patient's bedside increased the odds of mortality by $5 \%$ [3].

Plasma is stored at $<-30^{\circ} \mathrm{C}$ and has to be thawed before transfusion usually at $37-40^{\circ} \mathrm{C}$. Thawing of plasma usually requires approximately $30 \mathrm{~min}$ using a conventional water-based plasma thawing device, e.g., plasmatherm (Barkey, Leopoldshöhe, Germany). The use of specially designed microwave ovens for thawing introduced in the late 1980s or thawing at higher temperatures can reduce thawing time [8-12]. Thawing at temperatures of $45^{\circ} \mathrm{C}$ is safe if the plasma is removed before thawing is completed. Otherwise the hemostatic capacity of the plasma is reduced [13].

Options to provide plasma for transfusion are summarized in Table 1: Primarily used is fresh frozen plasma (FFP) after quarantine storage and thawing at the time of transfusion request. Storage of plasma directly after blood donation without freezing is approved by the Food and Drug Administration (FDA) in the USA, called liquid plasma, with a shelf life up to 26 days [14]. Liquid plasma is not an option in Germany because of the risk of pathogen transmission. As an alternative it is accepted by the FDA to store FFP at $1-6^{\circ} \mathrm{C}$ for up to $24 \mathrm{~h}$ after thawing and to relabel it as thawed FFP (tFFP) for further storage for up to 4 days at $1-6^{\circ} \mathrm{C}$ [14] based on data by Downes et al. [15] and others [16-20]. Freeze-dried (lyophilized) plasma can be used after reconstitution directly before transfusion [21]. With Lyoplas ${ }^{\circledR}$ (German Red Cross NSTOB, Germany), such a product is available in Germany, but reconstitution takes time and the development of foam during reconstitution seems to be sometimes a problem for the transfusing physician. Spray-dried plas- ma, also called on-demand plasma, is under investigation but not yet available [22].

The German hemotherapy guidelines accept for FFP a factor VIII activity after thawing of at least $70 \%$ of the value before freezing [23]. There are no definitions for minimal clotting factor activities in the product for plasma therapy, and no data from clinical studies are available assessing the efficacy of FFP or liquid plasma transfused after variable days of storage after thawing. Based on the experiences in treatment of severely injured military casualties [24], the recommendation for development and use of a massive transfusion protocol rose [25]. All massive transfusion protocols require the immediate availability of plasma for transfusion.

Under conditions of quarantine storage of plasma to reduce pathogen transmission, thawing of plasma and storage of thawed plasma for up to 7 days has been established by University Medicine Greifswald in 2011. Here we report our experience of working with this thawed plasma bank.

\section{Organization of the Thawed Plasma Bank}

Plasma is produced and stored by the manufacturer according to specifications approved by the regulatory body Paul Ehrlich Institute. Hemotherapy-qualified physicians (transfusion committee of the hospital with its head "Transfusionsverantwortlicher") establish and supervise the organizational structure of hemotherapy in the hospital, including management of the blood bank according to the German hemotherapy guidelines [23]. 


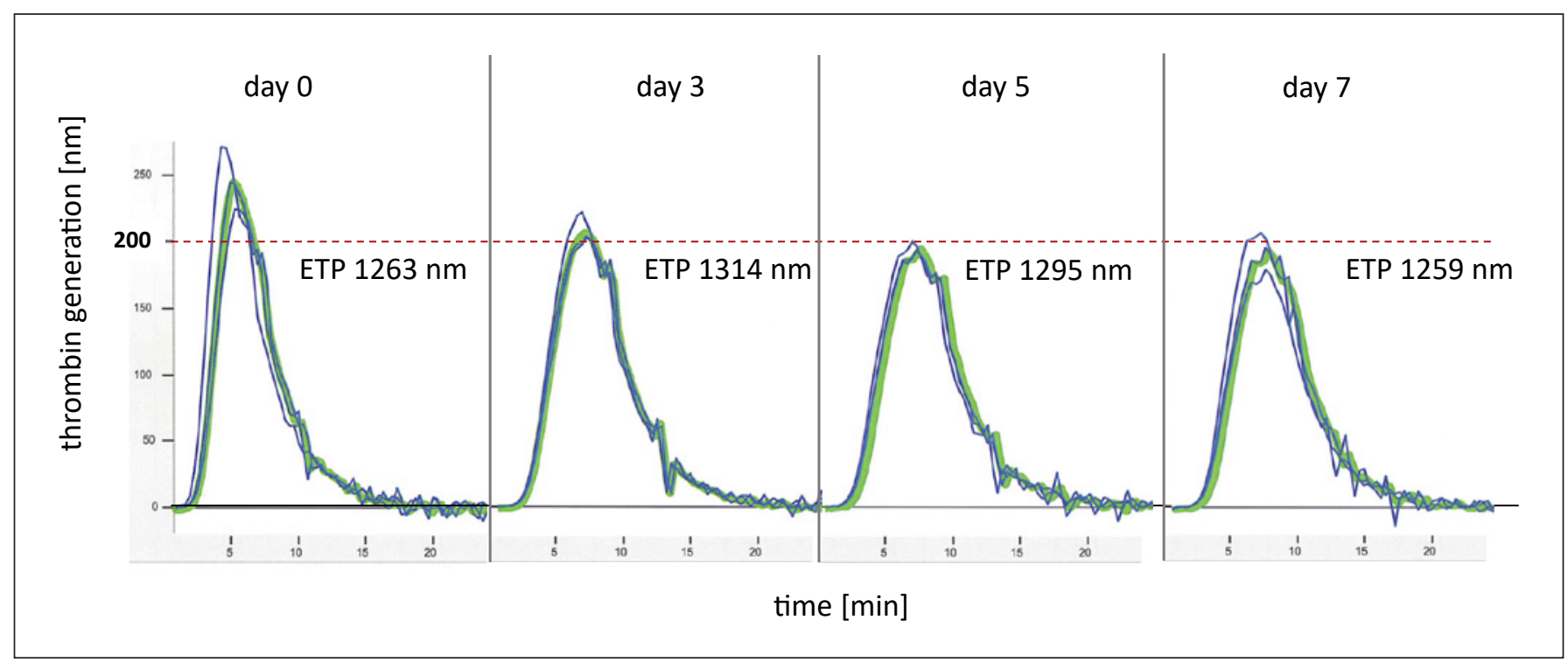

Fig. 1. Representative results of the endogenous thrombin generation potential (ETP) of one thawed plasma (three measurements of the same plasma at each time point) immediately after thawing (day 0 ), on days 3,5 and 7 and storage at $2-6^{\circ} \mathrm{C}$. Although the thrombin peak is slightly reduced, the time to peak and overall thrombin generation (area under the curve) do not differ between day 0 and day 7 as both pro- and anticoagulatory factors decrease [17].

The hemotherapy guidelines recommend storage of plasma after validation of specified conditions and immediate transfusion after release of thawed plasma from the blood bank to the recipient [23]. This allows storage of thawed plasma as part of the quality management system of hemotherapy. Specific conditions require individualized regulations for each hospital, including validation and standard operation for plasma processing and transfusion. Accordingly, we performed extensive validation of clotting factor activities using 50 thawed apheresis plasmas to evaluate the hemostatic quality of thawed FFP over 7 days $[16,17]$. Plasma units were divided into three biologically identical subunits and either stored for 7 days at $4^{\circ} \mathrm{C}$, at room temperature, or at $4^{\circ} \mathrm{C}$ after methylene blue/ light treatment. Single clotting factor activities (II, V, VII, VIII, IX, X, XI, XII, XIII, fibrinogen, antithrombin, von Willebrand factor antigen, protein $\mathrm{C}$ and $\mathrm{S}$ ) and functional hemostasis assays (aPTT, PT/INR, endogenous thrombin generation, and ProteinC ${ }^{\circledR}$ Global) were assessed after thawing and on days 3, 5, and 7 . Thawed FFP stored at $4^{\circ} \mathrm{C}$ for 7 days revealed major changes (activities outside the reference range) only for factor VIII (median $56 \%$, range $33-114 \%$ ) and protein S (median 51\%, range $20-88 \%$ ). The most pronounced decrease in factor VIII and protein $S$ activity occurred within the first 3 days after thawing (about $50 \%$ and $15 \%$, respectively). Thereafter, a further decrease in activity occurred within a $10 \%$ range compared to day 3 . The storage for 7 days at room temperature affected activities of all clotting factors and inhibitors except for protein C [16].
The endogenous thrombin generation potential remained stable after storage at $4^{\circ} \mathrm{C}(1,287 \pm 283 \mathrm{nmol}$ vs. $1,260 \pm 278 \mathrm{nmol} ; p=$ not significant; a representative example is shown in Fig. 1) [17]. The change in procoagulatory factors is commpensated by the concomitant decline of the anticoagulatory factors resulting in a new balance. INR and aPTT showed only modest alterations.

Although reports about clotting factor activities after storage of thawed plasma at $1-6^{\circ} \mathrm{C}$ for several days are sometimes controversial $[15,18,26-33]$, a general finding of these studies is that storage is feasible without relevant impairment of hemostatic activity of plasma. Published data have been generated with thawed apheresis as well as with whole-blood (recovered) plasma. Recovered plasma is often later shock-frozen than apheresis plasma, and clotting factor activities might therefore be lower. Whether this has any impact on clinical efficacy is unresolved. No clinical studies or prospective trials evaluating the clinical efficacy of tFFP (apheresis or recovered) in relation to storage time are available.

\section{Patient Populations to Whom Thawed Plasma Is Issued}

Situations of massive transfusion are relatively rare. Maintaining a thawed plasma bank for massive transfusion only would result in a major wastage rate. In this case, we expected that the majority of plasmas would be stored up to the end of the storage period (7 days). We therefore provide thawed plasma to all patients for whom plasma is requested, with the exception of pediatric pa- 
Table 2. Trauma management policy of University Medicine Greifswald includes consecutively issued trauma boxes by the blood bank, which contain a defined number of blood products for massively bleeding patients

Blood type of the patient is unknown (admission of a severely bleeding patient with unknown blood type to the emergency room)

\begin{tabular}{ll}
\hline First medical care supported by a & $4 \mathrm{RBCs}$ blood type O (Rh-positive) \\
sub-depot of blood products in the & $4 \mathrm{~g}$ fibrinogen concentrate \\
emergency room & $2,400 \mathrm{U}$ prothrombin complex concentrate \\
\hline Trauma box 1 (issued by the blood & $4 \mathrm{RBCs}$ blood type O (Rh-positive) \\
& $2 \mathrm{tFFP}$ blood type AB (from the thawed plasma bank) \\
& 1 platelet concentrate \\
& $4 \mathrm{~g}$ fibrinogen concentrate
\end{tabular}

Blood type of the patient is determined (a blood sample was received and serological testing of the ABD red cell antigens was performed; FFP is freshly thawed)

\begin{tabular}{ll}
\hline Trauma box 2 & 4 RBCs compatible with the patient's ABO blood type, Rh-positive \\
& 4 FFP compatible with the patient's blood type or tFFP blood type $A$ \\
& 1 platelet concentrate \\
& $2 \mathrm{~g}$ fibrinogen concentrate \\
\hline Trauma box $3,4, \ldots$ (until bleeding is & $4 \mathrm{RBCs}$ compatible with the patient's ABO blood type, Rh-positive \\
stopped or the anesthesist orders & $4 \mathrm{FFP}$ compatible with the patient's blood type \\
special products) & 1 platelet concentrate \\
& $2 \mathrm{~g}$ fibrinogen concentrate
\end{tabular}

FFP, fresh frozen plasma; tFFP, thawed stored plasma.

tients and patients with known single clotting factor deficiencies for whom clotting factor concentrates are available. All other patients, including patients with liver disease, receive thawed plasma. Importantly, patients do not receive more than 4 units of thawed stored plasma because not more than 4 units are thawed in advance. All additional plasma demand is supplied by freshly thawed FFP.

\section{Impact on Blood Bank Management}

The use of the thawed plasma bank has reduced workload and stress factors for the technologists of the blood bank. In case of emergencies, plasma can be issued immediately, and also regular requests from the operation theater, the intensive care unit, or any ward can be handled without time delay. This allows the staff to focus on organizational issues associated with the management of bleeding emergencies. In addition, storage of thawed plasma allowed to introduce a trauma management policy at our hospital, including early plasma transfusion and achievement of an RBC:plasma transfusion ratio of at least 2:1 immediately after hospital admission of the patient. With activation of this massive transfusion protocol a "trauma box" is issued to the emergency room containing a defined number of blood products shown in Table 2 . Special in-hospital transport staff is activated by phone call (the number is unique for this emergency situation), who then transports the trauma boxes and blood samples of the patient between the blood bank and the emergency room.
The thawed plasma bank has also improved the workflow in the operating room. Plasma can now be ordered when transfusion is definitely indicated. Before the availability of thawed plasma, the anesthetist had to plan always 30-60 min in advance and to order plasma prospectively in case plasma transfusion might be needed; if not needed, the thawed plasma was wasted or transfused based on a weak indication. Furthermore, for surgery with high risk of acute major blood loss (risk of arterial bleeding), we now provide RBCs and thawed plasma in a stand-by cooling container in the operating room. If the RBCs and plasma are not needed, they can be returned to the blood bank and further stored for the next transfusion request. For reintegration of the blood products, the cooling chain must not have been interrupted (monitored by a minimum-maximum thermometer). The annual plasma consumption has declined from a mean of 4,386 units between 2010 and 2016 to 1,779 units in 2020 (Fig. 2). However, due to the parallel establishment of patient blood management with stricter consideration of plasma transfusion indication and use of blood products, it is difficult to differentiate the effects of the patient blood management program and of the thawed plasma bank. Nevertheless, plasma wastage rate has to be evaluated and weighed against the advantages of a thawed plasma bank.

Storage time of the thawed plasma is often a matter of concern. To keep storage times short, we issue all plasma requests from the thawed plasma bank. When plasma is issued from the blood bank, FFP is immediately thawed and the plasma bank is restocked. This results in short 
Fig. 2. Overall consumption of plasma from the thawed plasma bank between 2011 and 2020 demonstrating the transfusion and wastage rate. The overall reduction in plasma transfusion in the hospital is also reflected by the reduction in tFFP in the thawed plasma bank. At the end of 2015 , type B plasma was omitted from the thawed plasma bank. However, if type B plasma had been issued as FFP and not transfused, the returned plasma bags were integrated into the thawed plasma bank. Total plasma includes freshly thawed and issued FFP and thawed plasma from the plasma bank. FFP, fresh frozen plasma; tFFP, thawed stored plasma.
Fig. 3. Issuing of plasma from the thawed plasma bank. More than half of the thawed units were issued within the first 2 storage days and $81 \%$ were issued within 3 days storage time. $\mathrm{tFFP}$, thawed stored plasma.
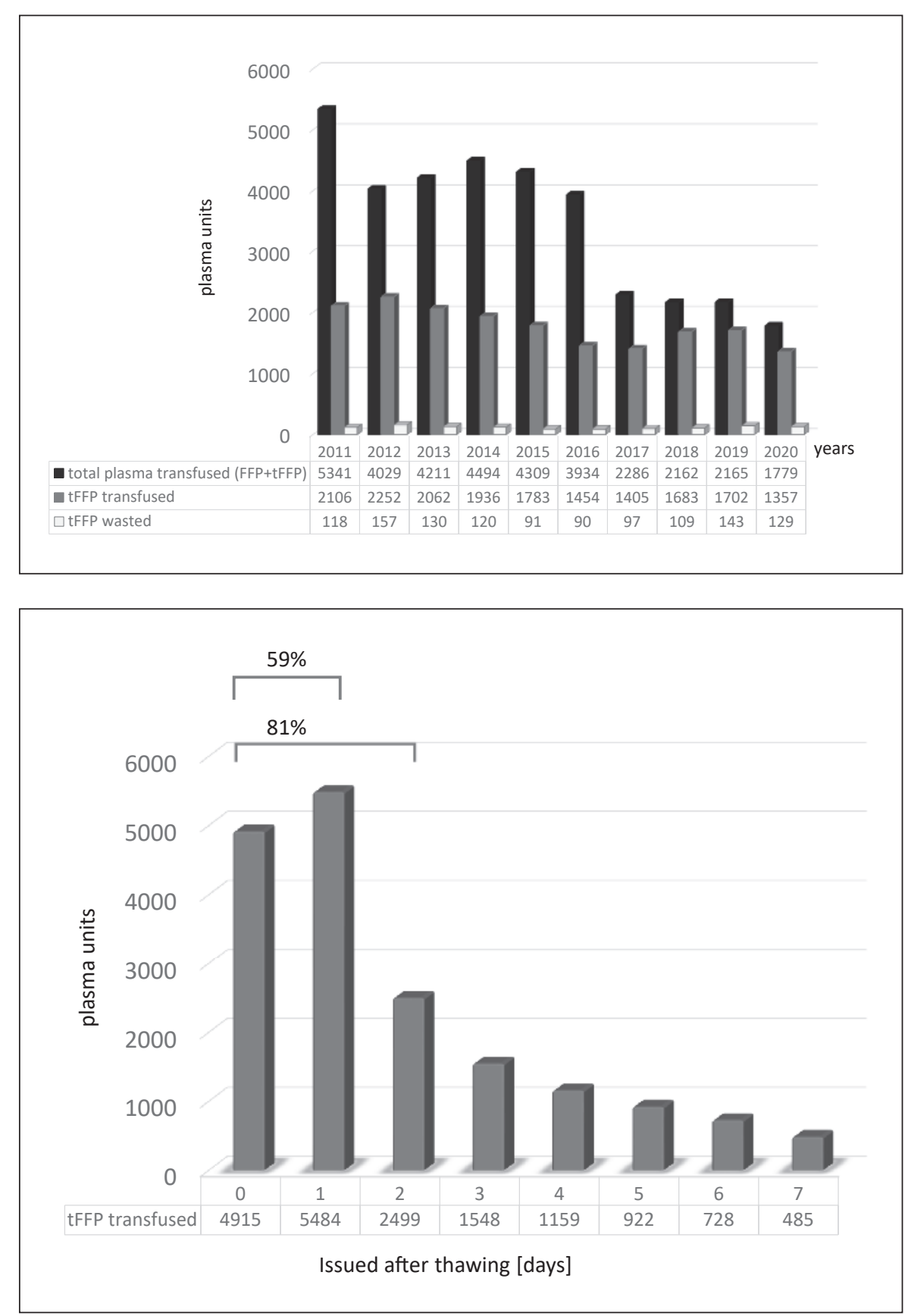

storage times of the thawed plasma units. During the 10year period most units (81\%) were issued within the first 3 days after thawing (shown in Fig. 3). The median storage time for thawed plasma was 1 day, the mean was 1.81 \pm 1.88 days. The overall wastage rate was $6.26 \%$ (Fig. 2 ). This is higher compared to the plasma wastage rate of about 3\% (2010: 3.13\%; 2018: 3.17\%; 2019: 2.92\%) reported to the Paul Ehrlich Institute by blood product users in Germany [34], but considering the decline in plasma consumption (by $24.5 \%$ within the first year and by $66.7 \%$ in 2020 compared to 2011), the introduction of the thawed plasma bank reduced the overall usage of plasma due to the advantages of "just in time" availability. Mostly plas- ma of blood type B (17.06\%) and blood type AB (8.13\%) expired in the thawed plasma bank. The lowest wastage rate and close to the overall wastage rate in German hospitals was plasma of blood type A (3.49\%). Blood type B patients are rare, and in case of transfusion requests for type B patients, type AB plasma can be used. Therefore, we stopped using type B plasma for the thawed plasma bank in 2015. The ideal product for the thawed plasma bank would be "universal plasma" without isoagglutinins, which can be transfused independently of the patient's blood group. We are currently developing such a product independently of blood type AB donors [35]. 


\section{Additional Advantages of the Liquid Plasma Bank}

A spinoff of our thawed plasma bank is the blood product supply for the helicopter emergency medical service (HEMS). Only with the background of a thawed plasma bank, the plasma supply for the helicopter allows an acceptable wastage rate of plasma because of the rare prehospital transfusion frequency. We provide type A thawed plasma for the HEMS to reduce AB plasma shortage. Since we introduced blood supply for the HEMS, the challenge for the management of the thawed plasma bank was to integrate the returned HEMS plasma without expanding the number of thawed plasmas and increasing their wastage rate.

\section{Possible Risks of the Thawed Plasma Bank}

There is the theoretical risk of bacterial growth in plasma during storage at $2-6^{\circ} \mathrm{C}$. This risk is not expected to be different from that of red cell concentrates for which 15-20 products are checked monthly after $>7$ days of storage ( $49 \pm 3$ days) [23]. Within 10 years we have not received a single report about a septic transfusion reaction after transfusion of tFFP. However, we have established an additional safety step. After quarantine storage, the frozen plasma bags are labeled and put into a vacuumsealed plastic bag. The thawed plasma is maintained in this plastic bag to reduce any risk of contamination from the outside in case of microlesions in the plastic bag, which may occur during handling of frozen plasma bags. This overpacking also allows easy discovery of minor leakage.

There could be a risk of providing insufficient clotting factors to a bleeding patient. However, the patient receives a maximum of four plasmas from the thawed plasma bank. Thereafter, freshly thawed FFP is issued. Thus, in any situation where more than four plasmas are transfused, there is no risk of clotting factor activity reduction. In situations where a maximum of four plasmas are transfused, the reduction in factor VIII of the 4 plasma units is barely relevant. This is especially true in patients with liver impairment who typically have elevated factor VIII levels. As the situation is different in newborns and children, we issue thawed plasma only for adult patients.

An additional potential risk of the thawed plasma bank is an increase in plasticizers dissolved from the blood bag into the lipids of the plasma [36]. Higher levels of diethylhexyl phthalate are present in plasma after 5 days of storage than in RBC units after 30 days of storage [36]. But again, the maximal number of tFFP transfused is limited to 4 units. With the introduction of new diethylhexyl phthalate-free whole-blood bag systems, e.g., 1,2-cyclohexane dicarboxylic acid diisononyl ester-containing blood bags, the risk of transmission of plasticizers can be reduced.

\section{Conclusion}

The thawed plasma bank of the University Medicine Greifswald has provided 18,924 thawed stored plasma units between 2011 and 2020. The workflow in the laboratory as well as in the emergency room, the operating room, and the intensive care unit have been optimized by thawed stored plasma. In case of emergencies, the stress factor for the transfusion medicine laboratory staff has been reduced substantially. The thawed plasma bank allows to transfuse patients with massive transfusion demand at the 2:1 ratio of RBCs and plasma according to guidelines. The "just in time" availability of plasma within the entire hospital has reduced precautionary ordering of plasma and hereby unnecessary use of plasma or wastage. As the overall approach to using blood products has changed over the last 10 years due to the patient blood management initiative, quantification of the effects of the thawed plasma bank in reduction of plasma units by a before-after comparison is problematic.

\section{Acknowledgment}

We thank Antje Westphal for extraction of data from the laboratory information system and her support in data analysis. We thank our technical assistants in the immunohematology laboratory for the management of the thawed plasma bank, including careful documentation and monitoring of plasma expiration after 7 days.

\section{Conflict of Interest Statement}

K. Selleng received research funding from Immucor, traveling support from SOBI, and consultant fees from Aspen outside the submitted work. A. Greinacher reports grants and nonfinancial support from Aspen, Boehringer Ingelheim, MSD, Bristol Myers Squibb, Bayer Healthcare, Instrumentation Laboratory; personal fees from Aspen, MSD, Macopharma, Bristol Myers Squibb, Chromatec, Instrumentation Laboratory; and nonfinancial support from Portola, Ergomed, and Biokit outside the submitted work.

\section{Funding Sources}

Establishing the thawed plasma bank at the Department of Transfusion Medicine of University Medicine Greifswald was funded by University Medicine Greifswald.

\section{Author Contributions}

K. Selleng and A. Greinacher analyzed the data and wrote the manuscript. 


\section{References}

1 Bundesärztekammer. Querschnitts-Leitlinien (BÄK) zur Therapie mit Blutkomponenten und Plasmaderivaten - Gesamtnovelle 2020. Bundesärztekammer; 2020 (cited June 20, 2021). Available from: https://www. bundesaerztekammer.de/aerzte/medizinethik/wissenschaftlicher-beirat/veroeffentlichungen/haemotherapietransfusionsmedizin/ querschnitt-leitlinie/.

2 Holcomb JB, del Junco DJ, Fox EE, Wade CE, Cohen MJ, Schreiber MA, et al. The Prospective, Observational, Multicenter, Major Trauma Transfusion (PROMMTT) study: comparative effectiveness of a time-varying treatment with competing risks. JAMA Surg. 2013; 148(2):127-36.

3 Holcomb JB, Tilley BC, Baraniuk S, Fox EE, Wade CE, Podbielski JM, et al. Transfusion of plasma, platelets, and red blood cells in a $1: 1$ : 1 vs a 1:1:2 ratio and mortality in patients with severe trauma: the PROPPR randomized clinical trial. JAMA. 2015;313(5):471-82.

4 Borgman MA, Spinella PC, Perkins JG, Grathwohl KW, Repine T, Beekley AC, et al. The ratio of blood products transfused affects mortality in patients receiving massive transfusions at a combat support hospital. J Trauma. 2007;63(4):805-13.

5 Brown LM, Aro SO, Cohen MJ, Holcomb JB, Holcomb JB, Wade CE, et al. A high fresh frozen plasma:packed red blood cell transfusion ratio decreases mortality in all massively transfused trauma patients regardless of admission international normalized ratio. J Trauma. 2011;71(2 Suppl 3):S358-63.

6 Spahn DR, Bouillon B, Cerny V, Duranteau J, Filipescu D, Hunt BJ, et al. The European guideline on management of major bleeding and coagulopathy following trauma: fifth edition. Crit Care. 2019;23(1):98.

7 Cardenas JC, Zhang X, Fox EE, Cotton BA, Hess JR, Schreiber MA, et al. Platelet transfusions improve hemostasis and survival in a substudy of the prospective, randomized PROPPR trial. Blood Adv. 2018;2(14):1696704.

8 Söhngen D, Kretschmer V, Franke K, Pelzer $\mathrm{H}$, Walker WH. Thawing of fresh-frozen plasma with a new microwave oven. Transfusion. 1988;28(6):576-80.

9 Churchill WH, Schmidt B, Lindsey J, Greenberg M, Boudrow S, Brugnara C. Thawing fresh frozen plasma in a microwave oven. A comparison with thawing in a $37^{\circ} \mathrm{C}$ waterbath. Am J Clin Pathol. 1992;97(2):227-32.

10 Kuta P, Hauck-Dlimi B, Strobel J, Zimmermann R, Eckstein R. Quality of clotting factor activity in fresh frozen plasma at thaw with a microwave system and after storage at $4^{\circ} \mathrm{C}$ for 48 hours. Clin Lab. 2016;62(6):987-91.

11 Bostrom F, Ekemar L, Olsson D, Egberg N, Lundahl J. Rapid thawing of fresh-frozen plasma with radio wave-based thawing technology and effects on coagulation factors during prolonged storage at $4^{\circ} \mathrm{C}$. Vox Sang. 2009; 97(1):34-8.
12 von Heymann C, Pruss A, Sander M, Finkeldey A, Ziemer S, Kalus U, et al. Thawing procedures and the time course of clotting factor activity in fresh-frozen plasma: a controlled laboratory investigation. Anesth Analg. 2006;103(4):969-74.

13 Plotz RD, Ciotola RT. Thawing of fresh-frozen plasma at $45^{\circ} \mathrm{C}$ versus $37^{\circ} \mathrm{C}$. Comparison using satellite packs of the same donor units. Am J Clin Pathol. 1988;89(3):381-4.

14 Cardenas JC, Holcomb JB. Time to plasma transfusion: a patient centered approach and modifiable risk factor. Transfusion. 2017; 57(4):869-73.

15 Downes KA, Wilson E, Yomtovian R, Sarode R. Serial measurement of clotting factors in thawed plasma stored for 5 days. Transfusion. 2001;41(4):570.

16 Thiele T, Kellner S, Hron G, Wasner C, Nauck M, Zimmermann K, et al. Storage of thawed plasma for a liquid plasma bank: impact of temperature and methylene blue pathogen inactivation. Transfusion. 2012;52(3):529-36.

17 Thiele T, Hron G, Kellner S, Wasner C, Westphal A, Warkentin TE, et al. Thrombin generation, ProC ${ }^{\circledast}$ Global, prothrombin time and activated partial thromboplastin time in thawed plasma stored for seven days and after methylene blue/light pathogen inactivation. Blood Transfus. 2016;14(1):66-72.

18 von Heymann C, Keller MK, Spies C, Schuster M, Meinck K, Sander M, et al. Activity of clotting factors in fresh-frozen plasma during storage at $4^{\circ} \mathrm{C}$ over 6 days. Transfusion. 2009; 49(5):913-20.

19 Tholpady A, Monson J, Radovancevic R, Klein K, Bracey A. Analysis of prolonged storage on coagulation factor (F)V, FVII, and FVIII in thawed plasma: is it time to extend the expiration date beyond 5 days? Transfusion. 2013;53(3):645-50.

20 Naghadeh HT, Maghsudloo M, Tabatabaei MR. Coagulation factors V, VIII, and X, prothrombin time and activated partial thromboplastin time test results in thawed plasma stored at $1-6^{\circ} \mathrm{C}$ for 5 days. Blood Transfus. 2011;9(1):95-8.

21 Bux J, Dickhörner D, Scheel E. Quality of freeze-dried (lyophilized) quarantined singledonor plasma. Transfusion. 2013;53(12): 3203-9.

22 Pusateri AE, Given MB, Schreiber MA, Spinella PC, Pati S, Kozar RA, et al. Dried plasma: state of the science and recent developments. Transfusion. 2016;56(Suppl 2):S128-39.

23 Richtlinie zur Gewinnung von Blut und Blutbestandteilen und zur Anwendung von Blutprodukten (Richtlinie Hämotherapie). Bundesärztekammer, Paul-Ehrlich-Institut/ Deutscher Ärzteverlag; 2017 (cited June 2, 2021). Available from: https://www.bundesaerztekammer.de/fileadmin/user_upload/ downloads/pdf-Ordner/MuE/Richtlinie_ Haemotherapie_E_A_2019.pdf.
24 Holcomb JB, Jenkins D, Rhee P, Johannigman J, Mahoney P, Mehta S, et al. Damage control resuscitation: directly addressing the early coagulopathy of trauma. J Trauma. 2007;62(2): 307-10.

25 Malone DL, Hess JR, Fingerhut A. Massive transfusion practices around the globe and a suggestion for a common massive transfusion protocol. J Trauma. 2006;60(6 Suppl):S91-6.

26 Alhumaidan H, Cheves T, Holme S, Sweeney J. Stability of coagulation factors in plasma prepared after a 24-hour room temperature hold. Transfusion. 2010;50(9):1934-42.

27 Bostrom F, Sjodahl M, Wehlin L, Egberg N, Lundahl J. Coagulation parameters in apheresis and leukodepleted whole-blood plasma during storage. Transfusion. 2007;47(3):4603 .

28 Cardigan R, Lawrie AS, Mackie IJ, Williamson LM. The quality of fresh-frozen plasma produced from whole blood stored at $4^{\circ} \mathrm{C}$ overnight. Transfusion. 2005;45(8):1342-8.

29 Lamboo M, Poland DC, Eikenboom JC, Harvey MS, Groot E, Brand A, et al. Coagulation parameters of thawed fresh-frozen plasma during storage at different temperatures. Transfus Med. 2007;17(3):182-6.

30 Scott E, Puca K, Heraly J, Gottschall J, Friedman K. Evaluation and comparison of coagulation factor activity in fresh-frozen plasma and 24-hour plasma at thaw and after 120 hours of 1 to $6^{\circ} \mathrm{C}$ storage. Transfusion. 2009; 49(8):1584-91.

31 Sidhu RS, Le T, Brimhall B, Thompson H. Study of coagulation factor activities in apheresed thawed fresh frozen plasma at $1-6^{\circ} \mathrm{C}$ for five days. J Clin Apher. 2006;21(4):224-6.

32 Wagner SJ, Kurtz J, Seetharaman S, Moroff G. Maintenance of coagulation factor activities and protein levels of frozen plasma and cryoprecipitate AHF following 1 year's storage at $-30^{\circ} \mathrm{C}$ with two 8 -hour temperature excursions to $-10^{\circ} \mathrm{C}$. Transfusion. 2013;53(11): 2827-8.

33 Yazer MH, Cortese-Hassett A, Triulzi DJ. Coagulation factor levels in plasma frozen within 24 hours of phlebotomy over 5 days of storage at 1 to $6^{\circ} \mathrm{C}$. Transfusion. $2008 ; 48(12): 2525-$ 30 .

34 Paul-Ehrlich-Institut. Berichte nach \$21 Transfusionsgesetz: Tabellen Gewinnung, Herstellung, Import, Export und Verbrauch 2019 und Auswertungen über mehrere Jahre. Paul-Ehrlich-Institut; 2020 (updated October 26, 2020; cited June 30, 2021). Available from: https: //www.pei.de/DE/newsroom/ pflichtberichte/21tfg/21-tfg-berichte-node. html; jsessionid=1A64D1ECC7B06423A1C7 A0BACEFA4684.intranet232.

35 Raster J, Greinacher A, Jacob M, Aurich K. Facilitating blood group independent plasma transfusion. Transfus Med Hemother. 2021; 48(suppl 1):1-82

36 Cardigan R, Green L. Thawed and liquid plasma - what do we know? Vox Sang. 2015; 109(1):1-10. 